\title{
Estado e mercado no transporte aéreo brasileiro pós-reformas
}

\author{
Cristiano Fonseca Monteiro*
}

\section{Resumo}

As mudanças ocorridas no transporte aéreo brasileiro após o ciclo de "reformas para o mercado" tornaram o setor objeto de crescente interesse. Este interesse se traduziu no surgimento de uma ampla literatura, caracterizada pela ênfase na agenda de liberalização e na crítica aos indícios de ativismo estatal. $\mathrm{O}$ artigo tem como objetivo confrontar este tipo de interpretação, incorporando abordagens inspiradas na Sociologia Econômica e nas análises institucionalistas para chamar atenção para a importância das variáveis de natureza política, com destaque para o Estado, no desempenho econômico. O contexto pós-reformas se caracteriza por um movimento inicial de maior ativismo estatal sobre o transporte aéreo, com a retomada de instrumentos regulatórios mais rígidos e a reabertura dos canais de diálogo entre atores estatais e empresas. Num segundo momento, o ativismo estatal é abandonado, ao mesmo tempo em que o setor alcança índices expressivos de crescimento, ultrapassando os limites da infra-estrutura de apoio ao vôo existente, processo que culminaria com o episódio do "apagão aéreo". A análise dos depoimentos de atores estatais e privados a respeito do "apagão" permite identificar nas deficiências do aparato estatal responsável pela atividade um dos fatores que conduziram ao “apagão". A conclusão do artigo chama atenção para a importância de se levar em consideração os condicionantes políticos, notadamente no que diz respeito ao papel do Estado, para o desenvolvimento do transporte aéreo brasileiro.

Palavras-chave: aviação comercial, política e economia, regulação, Sociologia Econômica, Institucionalismo Histórico.

* Doutor em Sociologia pela UFRJ. Professor Adjunto da Escola de Ciências Humanas e Sociais de Volta Redonda/UFF. Endereço eletrônico: fonsecamonteiro@ yahoo.com.br. 


\section{Introdução}

Em quase duas décadas de "reformas para o mercado", o transDorte aéreo brasileiro se tornou objeto de crescente interesse no debate público. $\mathrm{O}$ fim de um conjunto de mecanismos de controle regulatórios, permitindo maior liberdade na fixação de preços e na exploração de rotas aéreas, conduziu a uma profunda transformação na estrutura e nos atores deste mercado. As empresas tradicionais - Transbrasil, Vasp e Varig - foram sucessivamente sendo eliminadas, e com elas, o antigo modelo focado nos passageiros de maior poder aquisitivo. A Tam, nos anos 1990, e a Gol, na década atual, emergiram como os novos líderes do setor, que se tornou mais popularizado, deixando para trás o glamour que representava voar nos anos pré-reformas.

Enquanto na virada para a década de 2000 a agenda do transporte aéreo estava fortemente marcada pelo debate sobre a crise das empresas - em alguns anos mais críticos, todas as principais transportadoras tiveram prejuízos -, os anos mais recentes se caracterizaram pelo vigoroso crescimento dos indicadores, tanto das empresas individualmente quanto do setor como um todo. Mesmo havendo apenas duas grandes companhias, detendo cerca de $90 \%$ do mercado, os passageiros passaram a se beneficiar de tarifas cada vez mais baixas e de uma maior oferta de vôos, pelo menos nos trechos com maior procura. Até mesmo os profissionais que haviam perdido seus empregos com a falência das companhias tradicionais passaram a ser disputados, sugerindo um quadro até certo ponto surpreendente para quem, até poucos anos atrás, estava acostumado a ouvir as recorrentes lamentações de empresários sobre as dificuldades enfrentadas por suas empresas.

O forte revigoramento do transporte aéreo se deveu tanto ao ambiente econômico mais favorável dos últimos anos, quanto à capacidade das próprias empresas de buscar novas estratégias mais adequadas ao novo cenário de maior competição. Tão surpreen-

1 Versão adaptada do paper apresentado no I Seminário Nacional de Sociologia Econômica, em Florianópolis, em 20/5/2009. Agradeço a Cécile Raud e à equipe do NUSMER pelo convite para participar do seminário. Agradeço também à Faperj e ao CNPq pelo apoio à pesquisa com base na qual o artigo foi redigido. 
dente quanto a "virada" produzida em relativamente curto espaço de tempo pelo setor, no entanto, foi o fato de que as mudanças empreendidas pelas empresas vieram redundar em uma nova crise, atribuída por um dos ministros do atual governo ao próprio crescimento alcançado. Para espanto de todos, a crise recente que foi logo batizada como "apagão aéreo", teria sido causada, justamente, pelo crescimento econômico do país e pelo sucesso do mercado em se reestruturar, explorando as oportunidades do ambiente mais liberalizado e mais flexível.

Em meio a tantas crises, o debate sobre o setor aéreo ganhou densidade nos últimos anos, com um progressivo aumento no número de trabalhos publicados no Brasil. Não obstante o incremento numérico e a sofisticação das análises, este debate tem sido amplamente dominado pelo mesmo tipo de abordagem, prevalecendo uma ênfase unilateral na liberalização como o melhor caminho para fazer frente aos desafios encontrados. ${ }^{2}$ Nesta literatura, o Estado aparece como elemento portador de uma racionalidade (política) que é percebida como nociva. Os indícios de ativismo estatal são tratados como indesejáveis, por representar um potencial desincentivo ao investimento, introduzindo um elemento perturbador à eficiência da ordem econômica. Nesse sentido, esta literatura reproduz a visão sobre Estado e mercado que marcou o auge das "reformas para o mercado", tratandoos como forças opostas, numa visão dicotômica e simplificadora, sintetizada na fórmula "mais mercado, menos Estado".

Este trabalho tem como objetivo confrontar este tipo de interpretação, incorporando abordagens alternativas que têm caracterizado o contexto "pós-Consenso de Washington" (DINIZ, 2007), chamando atenção para o papel desempenhado pelas variáveis de natureza política, com destaque para o Estado, no desempenho econômico. $\mathrm{O}$ artigo sustenta que a abordagem dicotômica sobre a relação entre Estado e mercado deve dar lugar a uma abordagem integrativa. Se no auge das reformas neoliberais a questão estava muito mais concentrada em quanto de Estado deveria haver na economia (a resposta de praxe sendo, sempre, o mínimo), abor-

2 Dentre os principais, estão: Franco et al. (2002); Pêgo Filho (2002); Guimarães e Salgado (2003) e Oliveira $(2005,2006)$. 
dagens alternativas têm convincentemente demonstrado que a questão-chave está em como se constitui esta relação, pois muito das experiências bem-sucedidas em fazer frente aos desafios do capitalismo globalizado tem sido explicado pela qualidade das relações entre Estado e mercado.

Este artigo é composto por três seções, além desta introdução. Na seção seguinte, será desenvolvida a discussão teórica sobre a relação entre Estado, mercado e política, com um balanço da literatura em Sociologia Econômica e das análises institucionalistas para sustentar uma visão alternativa à que inspirou a agenda de reformas. As duas seções seguintes são dedicadas à discussão empírica. $\mathrm{Na}$ primeira delas, é discutida a dinâmica das relações entre Estado e mercado entre os anos de 2003 e 2004, quando o ciclo de reformas para o mercado dá lugar a uma retomada do ativismo estatal no setor, empreendendo-se uma tentativa de re-regulação do mercado de transporte aéreo brasileiro e de retomada do diálogo entre atores estatais e empresas aéreas. A seção seguinte aborda o período compreendido entre os anos de 2005 e 2007, quando a agenda do ativismo estatal e de retomada do diálogo é abandonada, ao mesmo tempo em que o setor assistiu ao ciclo de crescimento que culminou com o episódio do "apagão aéreo". Nesta seção, são discutidos os diagnósticos apresentados por diferentes atores estatais e privados ligados à atividade. Uma seção conclusiva confronta os argumentos presentes na literatura econômica sobre o setor com os apresentados ao longo do trabalho, sugerindo algumas contribuições para o debate sobre as policies para o transporte aéreo brasileiro.

\section{Estado, mercado e política: uma abordagem integrativa}

As incertezas e dificuldades enfrentadas pelo transporte aéreo brasileiro neste início de século XXI estão relacionadas às mudanças características de um capitalismo globalizado e competitivo. A relação entre política e economia e, mais especificamente, entre Estado e mercado, tem estado no centro do debate sobre as estratégias para fazer frente a este novo cenário (Cf. DINIZ, 2000, 2007). Inicialmente, as interpretações sobre esta nova ordem sugeriram 
que as pressões competitivas e a necessidade de investimentos privados fariam as diversas trajetórias nacionais convergirem para um padrão mais homogêneo de "economia de mercado". Nesta nova ordem, a política cederia espaço diante do peso das forças econômicas, restringindo sobremaneira a capacidade de fazer escolhas a respeito das estratégias de inserção. ${ }^{3}$ O Estado, como ator central na definição destas estratégias, teria sua capacidade de ação limitada à criação de um ambiente favorável ao livre curso das forças econômicas, sob pena de ser punido com a "fuga" dos investimentos para localidades em melhores condições.

Junto com estas interpretações, assistiu-se ao fortalecimento da agenda neoliberal, preconizando como a melhor estratégia de inserção no capitalismo globalizado a liberação da atividade econômica dos constrangimentos de natureza política, apostando na capacidade dos mercados de se auto-regular e, assim, promover uma "alocação eficiente" dos recursos. ${ }^{4}$ Nestes termos, a ação estatal deveria se limitar à manutenção de um ambiente macroeconômico "saudável" para o investimento privado (com inflação controlada e orçamento equilibrado), admitindo-se, em alguns casos, como em setores de infra-estrutura e serviços públicos, uma ação regulatória de caráter exclusivamente técnico. ${ }^{5}$ Daí a adoção do modelo de agências reguladoras "autônomas", sempre tendo em vista a manutenção de um ambiente favorável aos investidores.

3 Para uma versão brasileira desta linha de argumentação, ver Bacha (1995). Berger e Dore (1996), Drache (1996) e Ferrer (1997), dentre outros, analisam criticamente os argumentos das "teorias da convergência", que o último chama de abordagens "fundamentalistas" sobre a globalização.

4 Ainda de acordo com a agenda neoliberal, políticas ativas de desenvolvimento e mecanismos de concertação aproximando atores estatais e interesses privados na definição de estratégias, por envolver decisões políticas, eram tidas como nocivas, gerando distorções e necessariamente beneficiando grupos específicos em detrimento do conjunto da sociedade.

5 Para alguns autores, as agências reguladoras seriam capazes de exercer uma autoridade sobre os agentes econômicos imune às injunções do jogo político, garantindo estabilidade ao funcionamento do mercado. Assim, este modelo permitiria distinguir claramente as tarefas de governo (desempenhadas pelos ministérios, por definição, envolvendo decisões políticas) e as tarefas de Estado, cuja estabilidade adviria do fato de se basearem em critérios técnicos (cf., entre outros, Souza e Moreira, 1995; Prado, 1996; e Rigolon, 1997). 
Não obstante, a despeito das previsões sobre a alegada convergência para um padrão mais ou menos homogêneo do sistema econômico, diferentes autores se esforçaram por demonstrar que as trajetórias nacionais de inserção no contexto da globalização foram marcadas por negociação, disputa e acomodação de interesses, ou seja, obedecendo a uma lógica eminentemente política (VELASCO \& CRUZ, 1998; DINIZ, 2000). Estudos empíricos viriam confirmar esta perspectiva (KIRSCHNER et al., 2002; LEOPOLDI, 1999; MONTEIRO, 2000), ao mesmo tempo em que se assistiu à retomada dos estudos sobre estratégias de desenvolvimento, notadamente no que diz respeito à permanência das escolhas políticas e ao papel do Estado (ARBIX, 2002; CHANG, 2002, 2004; DINIZ, 2000, 2007). 6

O caráter estruturante do Estado vis-à-vis o mercado é um tema presente nas obras clássicas (POLANYI, 1944) e contemporâneas (BOURDIEU, 1997, FLIGSTEIN, 2001) da Sociologia Econômica. Num ensaio publicado na primeira edição do Handbook of Economic Sociology, Fred Block desenvolve este tema e propõe uma ruptura com a visão "dualista" que coloca Estado e mercado como entidades analiticamente separadas, dando lugar a uma visão integrada da relação entre ambos (BLOCK, 1994). Assim, o paradigma tradicional, cujo pressuposto é a existência de diferentes graus de intervenção do Estado sobre a economia (criando-se, assim, um continuum que iria de um Estado puramente liberal até um Estado puramente intervencionista), deixa de fazer sentido, devendo ser substituído por um novo paradigma que privilegie as diferentes formas de relação entre ambos.

6 Como salienta Eli Diniz (2007, p. 24-33), não se trata da retomada do antigo modelo de Estado nacional-desenvolvimentista, que as crises dos anos 1980 e início dos 1990 revelaram ultrapassado. Tampouco se trata de negar que a globalização trouxe desafios à autonomia do Estado-Nação. Trata-se, como propõe a autora, de enfrentar os desafios à governabilidade, que não se colocam apenas no plano interno, mas também na inserção externa, envolvendo a menor vulnerabilidade às oscilações do mercado internacional, a redução das desvantagens comparativas em relação às economias desenvolvidas e a construção de mecanismos de regulação da economia global. Assim, a autora defende a necessidade de se explorar as margens de manobra existentes, num tipo de ação estratégica que diferentes autores têm associado aos casos bemsucedidos de desenvolvimento. 
A "abordagem institucional comparativa" proposta por Peter Evans para analisar o desenvolvimento da indústria de tecnologia da informação na Coréia do Sul, na Índia e no Brasil (Evans, 1995) se insere neste novo paradigma ao demonstrar que o sucesso sul coreano em promover uma indústria de TI internacionalmente competitiva se deu graças a um Estado capaz de produzir uma relação de "autonomia e parceria" com o capital privado. ${ }^{7}$ Os estudos reunidos em Hollingsworth et al. (1994) e Hollingsworth e Boyer (1997), sobre os países desenvolvidos, e aqueles reunidos em Maxfield e Schneider (1997), sobre os países em desenvolvimento, são exemplos adicionais de abordagens que identificam nos padrões de articulação entre Estado e mercado a variável que explica as diferentes trajetórias nacionais e setoriais de sucesso. ${ }^{8}$

Substituindo as abordagens econômicas convencionais que deram ênfase a uma interpretação dicotômica da relação entre Estado e mercado, na qual a pergunta principal era "quanto de Estado deve haver na economia?”, as análises supracitadas procuraram abordar esta relação de forma integrada, mudando a pergunta para “como Estado e mercado devem se relacionar?". No lugar da ênfase unilateral na propensão de que a aproximação entre atores estatais e empresários seria geradora de colusão, práticas de rent seeking e afins, estes trabalhos procuram demonstrar que a articulação entre ambos também pode gerar maior troca de informações, confiança (e consequientemente, maior propensão ao investimento), reciprocidade e credibilidade de parte a parte.

7 A coerência interna das instâncias burocráticas responsáveis pela promoção do desenvolvimento, (dimensão da autonomia) e os laços formais e informais ligando agentes estatais aos agentes privados (dimensão da parceria), garantiriam um relacionamento entre Estado e mercado capaz de gerar fluxo de informações, um clima de confiança para os investidores, ao mesmo tempo que evitaria que agentes estatais - recrutados com base em critérios meritocráticos, com salários competitivos em relação ao setor privado e dotados de alta qualificação técnica - fossem capturados pelos interesses privados.

8 Além destes, os trabalhos de Weiss (1998) e Hicks e Kentworth (1998) também abordam a relação Estado e mercado de um ponto de vista integrativo, focado na dimensão sócio-política. Para um balanço mais extenso desta literatura, ver Diniz (2000, cap. 3). 
Com base neste arcabouço, a seção seguinte se dedica a analisar a qualidade das relações entre Estado e mercado no transporte aéreo brasileiro no contexto pós-reformas, compreendido entre os anos de 2003 e 2007.

\section{Ativismo estatal e a retomada do crescimento no transporte aéreo brasileiro}

De um ambiente altamente regulado até o início dos anos $1990,{ }^{9}$ o transporte aéreo brasileiro foi assumindo uma feição cada vez mais liberalizada à medida em que foi se aproximando do século XXI. Na virada do século, estavam extintas todas as restrições na oferta de descontos, oferta de vôos e uso de aeroportos. Embora tenha sido introduzida por Fernando Collor, a agenda de liberalização teve seu auge no primeiro mandato de Fernando Henrique Cardoso. Em seu segundo mandato, Fernando Henrique colocou em pauta a reformulação do aparato regulatório do transporte aéreo - a criação da Agência Nacional de Aviação Civil (ANAC), em substituição ao Departamento de Aviação Civil (DAC), a reforma do Código Brasileiro do Ar e a privatização da Infraero, estatal responsável pela gestão dos principais aeroportos brasileiros -, ao mesmo tempo em que o setor inicia um período de grave crise que atingiria todas as empresas em operação. É também neste contexto que a ampla coalizão de apoio à agenda neoliberal formada após o Plano Real começa a se enfraquecer, à medida em que surgem demandas em diferentes setores da sociedade, inclusive na base de sustentação do governo, por uma nova agenda de desenvolvimento.

9 A regulação do transporte aéreo brasileiro se baseou, entre as décadas de 1960 e início dos anos 1990, nos princípios da "realidade tarifária" e da "competição controlada". O primeiro deles significava que eram os usuários do transporte aéreo que deveriam arcar com os custos dos serviços prestados, o que significaria o fim dos subsídios recebidos pelas empresas em todas as suas operações. O segundo, a "competição controlada", visava eliminar o que se entendeu constituir práticas "ruinosas" para o mercado, tais como voos de diferentes empresas partindo no mesmo horário sem ocupação que os justificasse, ou a oferta de descontos capazes de levar as empresas a uma concorrência predatória, colocando em risco a segurança dos voos. Para um balanço, ver Monteiro (2004, cap. 3). 
O ciclo das reformas, além de liberalizar os mercados, caracterizou-se pela desconstrução dos principais canais de consulta e negociação entre atores estatais e agentes privados que haviam caracterizado os anos do nacional-desenvolvimentismo. Embora permanecessem fortes os laços unindo autoridades aeronáuticas e empresários ao longo dos anos 1990, as políticas para o transporte aéreo passaram a ser implementadas a partir de instâncias mais próximas do Executivo, e também neste caso se reproduziu o estilo avesso à interlocução com agentes privados típico daquele ciclo. Na falta de canais institucionalizados de interlocução com o governo, este período se caracterizou pela mobilização dos empresários junto à opinião pública e ao Congresso, como o apoio dos trabalhadores (Cf. MONTEIRO 2006, 2008), em torno de uma agenda de redução de encargos, redução da burocracia e equiparação das condições de competição com as empresas estrangeiras. Uma reversão do isolamento entre o Executivo e as empresas se daria apenas ao final do governo Fernando Henrique, com a criação do Fórum de Competitividade do setor aéreo em 2002. ${ }^{10}$

Poucos meses depois de encerrados os trabalhos do Fórum, tomaria posse como presidente da República Luís Inácio Lula da Silva, fortalecendo a expectativa de mudanças. Como têm sugerido trabalhos recentes (Cf. DINIZ, 2006; DINIZ \& BOSCHI, 2007), a chegada do Partido dos Trabalhadores ao poder representou ao mesmo

10 No Fórum de Competitividade, as empresas lograriam obter do governo medidas que atendiam a algumas de suas demandas. As medidas incluíram perdão da dívida do PIS e da Cofins relativas ao período 1988-1999; assunção pelo governo do seguro anti-terrorismo criado após os atentados de 11 de setembro; extinção do pagamento de Imposto de Renda retido na fonte (até dezembro de 2003); redução de 7,05\% para zero da alíquota do IOF sobre o seguro de responsabilidade civil; ampliação dos casos de isenção do imposto de importação de peças de reposição de aeronaves; diminuição do prazo de desembarque de peças importadas e abertura de crédito pelo BNDES. Rego Filho (2002) faz uma análise destas medidas que representa bem a abordagem da literatura econômica sobre o setor, considerando-as um típico ato de caráter paternalista ("político"), que prejudicaria o conjunto da sociedade por representar desincentivo à competitividade. Ainda consistente com a literatura econômica, o autor desconsidera a dinâmica política por trás destas medidas, que passou pelo reconhecimento da necessidade de se reduzir os encargos sobre as empresas brasileiras de forma a equiparar suas condições de competitividade às das estrangeiras. 
tempo continuidade e ruptura em relação ao governo Fernando Henrique Cardoso. Por um lado, afirmou um forte compromisso com a manutenção da política macroeconômica focada na estabilidade dos preços. Ao mesmo tempo, sinalizou com a retomada de estratégias mais ativas no que diz respeito ao papel do Estado na promoção do desenvolvimento, assim como retomando os canais de interlocução entre Estado e agentes privados abandonados nos anos 1990, de que a criação do Conselho de Desenvolvimento Econômico e Social (CDES) seria o maior exemplo (Cf. TÁPIA, 2007).

Como se depreende da leitura de reportagens publicadas nos primeiros meses de 2003, empresários e trabalhadores do transporte aéreo aproveitariam a sinalização do novo governo de retomar os canais de interlocução com o setor produtivo e se mobilizaram para levar às autoridades suas demandas, cujo teor continuava a girar em torno da busca de soluções para a crise estrutural em que se encontravam as empresas. Do ponto de vista dos empresários, permaneciam as demandas em torno de "melhores condições de competitividade" para as empresas brasileiras. A despeito das conquistas pontuais obtidas no Fórum de Competitividade de 2002, uma série de itens permanecia "em aberto" na pauta dos empresários. O custo do querosene de aviação, encargos fiscais, deficiências na infraestrutura de apoio ao vôo e a própria criação da ANAC figuravam como os principais itens.

De uma série de encontros entre o Executivo, empresários e sindicatos travados neste período, amadureceria a tese de que a crise vivida pelo conjunto do setor era uma "crise de superoferta". Assim, a solução para tal quadro passaria necessariamente pela retomada, em algum grau, de mecanismos regulatórios sobre a oferta, revertendo o ciclo de liberalização dos doze anos anteriores, para que as empresas reencontrassem o equilíbrio financeiro. Havia também certo consenso a respeito da necessidade de se buscar uma solução para o problema específico da Varig, sob a justificativa de que se tratava de uma empresa cuja atuação, especialmente nas linhas internacionais, tinha caráter estratégico para o país. Por outro lado, representantes do governo salientaram que qualquer solução, seja para o setor em geral, seja para a Varig em particular, não deveria envolver a concessão de apoio financeiro direto. 
O fortalecimento da tese da "crise de superoferta" dentro do governo seria a oportunidade para que os militares da Aeronáutica reavivassem o princípio da "competição controlada", adotando uma regulação mais rígida para o mercado. Assim, ainda em março de 2003, o Comando da Aeronáutica publicaria a Portaria n 243/GC5, visando "promover a adequação da indústria de transporte aéreo à realidade do mercado". ${ }^{11}$ Baseando-se no Código Brasileiro de Aeronáutica de 1986, a portaria estabelecia uma série de medidas visando restringir a oferta de vôos. Seus artigos mais importantes são os de número 1,2 e 4, os quais determinam a adoção de medidas de adaptação da oferta das empresas à demanda, o desenvolvimento de planos de "racionalização" das linhas e a restrição à importação de aeronaves, processo que passaria a depender de autorização do DAC, sujeito "à comprovação de real necessidade por parte do requerente". ${ }^{12}$

Ao mesmo tempo em que o DAC revertia o processo de liberalização, o Ministério da Defesa, liderando as iniciativas do Executivo para o setor, dava continuidade ao diálogo dentro e fora do governo para a busca de soluções para a crise. Desta forma, no início de abril de 2004, o ministro José Viegas anunciou a criação de dois comitês técnicos, um para tratar do problema específico da Varig, reunindo representantes de diferentes órgãos do governo, e outro para discutir soluções de caráter mais estrutural, de caráter tripartite, com representantes do governo, das empresas e dos trabalhadores. ${ }^{13} \mathrm{O}$ "Comitê Técnico de Políticas Públicas", dedicado às questões estruturais do setor, apresentaria em maio de 2003

11 Ver Ministério da Defesa/Gabinete do Comandante da Aeronáutica/Comando da Aeronáutica, Portaria 243/GC5, 13/3/2003. Disponível via http://www.anac. gov.br/biblioteca/portarias/port243GC5.pdf (Consultado em 5/10/2008).

12 Id.. Em julho daquele ano, o Comando da Aeronáutica publicaria nova portaria, desta vez alterando as próprias "Diretrizes para o Transporte Aéreo Nacional" que haviam sido estabelecidas em 1992, no início do processo de liberalização. O texto desta portaria avança na regulação do mercado definindo critérios para a própria entrada de novos agentes, determina que se evite a "superposição de linhas" e, por fim, reforça a determinação de que a competição via preços não pode comprometer a saúde financeira das empresas. Ver Ministério da Defesa/Comando da Aeronáutica, Portaria n. 731/GC5, 31/7/2003. Disponível via http://www. anac.gov.br/biblioteca/portarias/Port0731GC5.pdf (consultado em 5/10/2008).

13 Segundo as fontes consultadas, o comitê dedicado ao problema da Varig não apresentaria resultados, sendo eventualmente abandonado. 
um conjunto de propostas ao Conselho Nacional de Aviação Civil (CONAC) e ao ministro da Defesa, que seriam aprovadas em outubro de 2003, sob a forma de dezessete resoluções. O texto destas resoluções confirmava a retomada de um modelo regulatório mais rigoroso sobre as empresas, mas avançava em direção a uma agenda de desenvolvimento mais ampla, ao abordar uma série de iniciativas relativas à modernização da infra-estrutura aeroportuária e de controle do espaço aéreo, medidas de desburocratização, financiamento para aquisição de aeronaves brasileiras, dentre outros. ${ }^{14}$

Como seria de se esperar, uma reversão de tal amplitude nas orientações das políticas para o transporte aéreo não se faria sem conflitos dentro do governo. Diante das medidas tomadas pelo Comando da Aeronáutica com apoio do Ministério da Defesa, outros setores, como o Turismo e a Fazenda, se mostrariam descontentes. Desta forma, consolidam-se neste período duas visões distintas no interior do governo a respeito do papel do Estado e das políticas para o transporte aéreo. De um lado, setores favoráveis à retomada de um maior ativismo estatal, sob a liderança do próprio ministro da Defesa, com apoio do BNDES e dos militares, e de outro, setores que defendiam o aprofundamento da liberalização, organizados no Ministério da Fazenda.

A retomada do ativismo estatal e do diálogo com as empresas, no entanto, seria abruptamente interrompida no segundo semestre de 2004, quando uma crise entre José Viegas e o Comando Militar levaria o primeiro a deixar o Ministério da Defesa. Em seu lugar, assumiria o vice-presidente José Alencar, que não levaria adiante a agenda construída pelo seu antecessor. Assim, entre fins de 2004 e início de 2005, as reuniões entre representantes do núcleo do governo para tratar de políticas estruturais para o setor, até então constantes, deixam

14 No que tange à regulação, ao mesmo tempo em que uma das resoluções indicava que caberia "ao mercado o papel principal de induzir que a oferta e a demanda se adequem mutuamente", outra previa possibilidade de regulação da oferta, podendo haver atuação "em caráter excepcional, em segmento específico do mercado", e o monitoramento das tarifas, cabendo medidas previstas no Código Brasileiro de Aeronáutica de 1986 em caso de "abusos". As resoluções do CONAC estão disponíveis em: https://www.defesa.gov.br/aviacao_civil/index. php?page=legislacao_aviacao_civil_2003 (consultado em 01/12/2007). 
de acontecer. A exceção fica por conta dos encontros dedicados à crise das empresas mais antigas, Vasp e Varig. No período, a empresa paulista sofreria uma intervenção do DAC, sob mandado judicial, e eventualmente paralisaria suas atividades. A empresa gaúcha, por sua vez, veria sua situação se tornar cada vez mais crítica. A despeito das sucessivas iniciativas do governo para encontrar soluções para a empresa, a sua controladora, Fundação Ruben Berta, vetaria todas as propostas que envolvessem perda de controle sobre a Varig.

As empresas Tam e Gol aproveitavam o espaço deixado pelas transportadoras mais antigas e o início de um ciclo de crescimento no setor para ampliar sua participação no mercado, oportunidade que também seria aproveitada por empresas novas ou recémcriadas, como a BRA, Oceanair e a Webjet, dispostas a expandir suas atividades. Com efeito, entre 2005 e 2007 o transporte aéreo brasileiro alcançaria expressivos índices de crescimento no segmento doméstico. O Gráfico 1 mostra que o tráfego aéreo dentro do país passou de um valor aproximado de 25 milhões de assentos/ $\mathrm{km}$ utilizados pagos entre 2001 e 2003 para mais de 40 milhões em 2007, um incremento de cerca de $60 \%$ em quatro anos. ${ }^{15} \mathrm{O}$ ciclo de crescimento instaurado a partir de 2004 seria acompanhado pela retomada da lucratividade da indústria. A análise do Gráfico 2 mostra que a retração dos primeiros anos da década, com prejuízo para o conjunto das empresas, seria superada já em 2003, quando começam a vigorar as medidas de restrição da oferta implementadas pelo DAC. A curva ascendente segue até 2004, quando as medidas são abandonadas, de modo que em 2005 a lucratividade cai, embora se mantenha positiva para este ano e o ano seguinte no segmento doméstico, voltando a se tornar negativa em 2007.

15 O mercado internacional, por sua vez, também ensaiaria uma recuperação a partir de 2004, mas sofreria forte redução em 2006, quando a Varig abandonou a maior parte das suas rotas internacionais. Embora o fluxo de passageiros internacionais voando de e para o Brasil tenha aumentado neste período, a participação das empresas brasileiras neste montante - que já vinha sofrendo redução desde a década de 1990 - sofreria mais uma queda. Segundo estudo da RPK Consultoria com base em dados do DAC e da ANAC, em 1990, as empresas brasileiras tinham participação de $53 \%$ no tráfego aéreo internacional com origem ou destino no Brasil. Em 2007, este número cairia para 23\% (Cf. RPK Consultoria, 2008). 


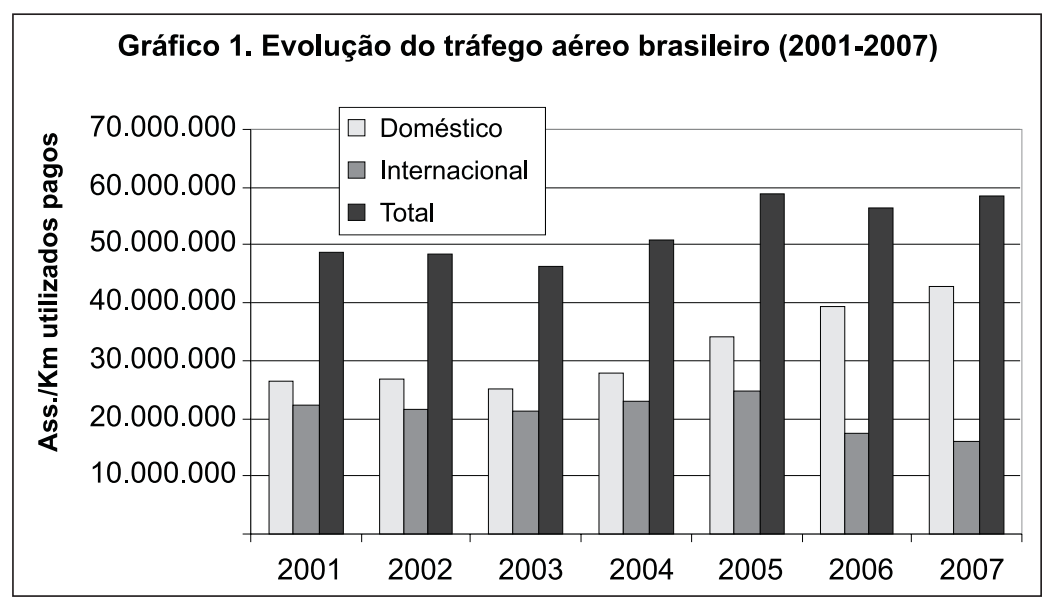

Fonte: Anuários estatísticos da ANAC.

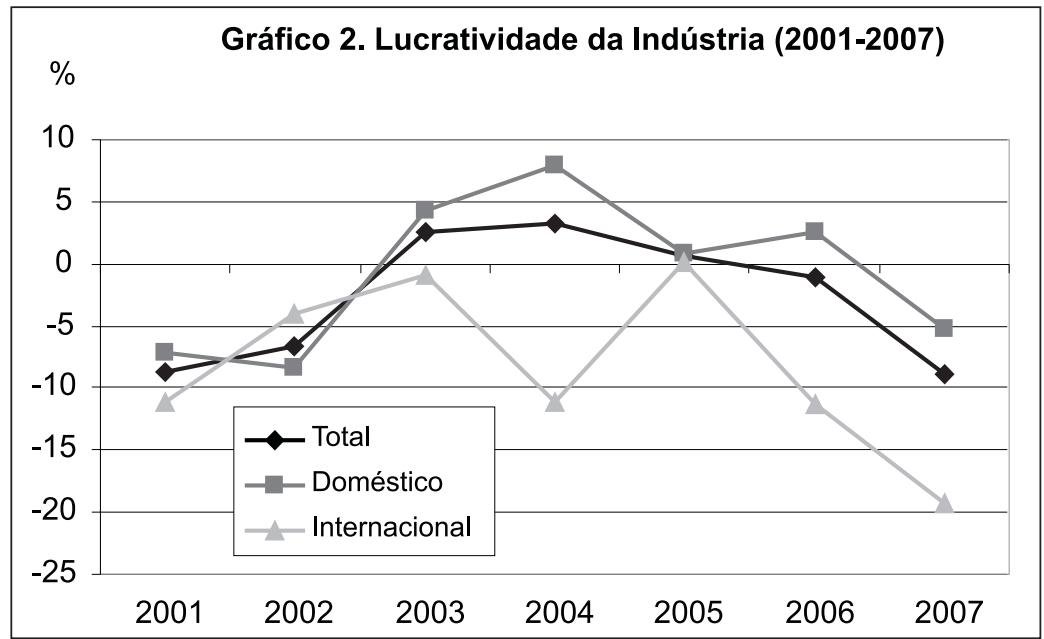

Fonte: Anuários Estatísticos da ANAC.

O rápido crescimento do transporte aéreo brasileiro no setor doméstico e a abrupta queda no segmento internacional representariam desafios distintos e, de certa forma, complementares no seu impacto sobre a gestão do transporte aéreo. É neste contexto que é finalmente criada a Agência Nacional de Aviação Civil (em março de 2006). Seus primeiros meses de trabalho coincidiriam com o progressivo abandono, por parte da Varig, da maior parte de suas 
rotas domésticas e a quase totalidade das rotas internacionais, nas quais a empresa ainda era responsável por cerca de $80 \%$ dos passageiros transportados dentre as empresas brasileiras. Em relação ao mercado doméstico, apenas um dia depois da instalação da nova agência, um avião da companhia aérea BRA derrapou na pista de Congonhas, levando a ANAC a convocar as empresas aéreas e a estatal responsável pela administração dos aeroportos, a Infraero, para negociar a redução das operações no aeroporto da capital paulista de modo a viabilizar uma reforma. Naquele momento, Congonhas já havia se consolidado como o principal hub da Gol e da Tam, ${ }^{16}$ de modo que qualquer alteração nos vôos passando por aquele aeroporto representaria um impacto sobre toda a malha aérea do país. O problema nas pistas de Congonhas, cujas consequiências seriam sentidas durante meses, seria apenas o primeiro de uma sucessão de eventos que demarcariam o episódio que ficou conhecido como o “apagão aéreo”, assunto que será aprofundado na próxima seção.

\section{O "apagão aéreo" e a qualidade da ação estatal}

O marco do "apagão aéreo" foi o acidente ocorrido com um Boeing 737-800 da Gol, que voava de Manaus para Brasília e foi atingido por um avião Legacy recém-saído da fábrica da Embraer, em São José dos Campos, com destino aos Estados Unidos. Após este acidente, começaria uma fase que ficaria reconhecida como a mais grave crise enfrentada pelo setor em décadas. Um dos fios

16 A concentração dos vôos em São Paulo se explica, em primeiro lugar, pela própria condição da cidade como centro econômico do país. Ao mesmo tempo, as empresas lançaram mão de um modelo de distribuição de rotas chamado hub-and-spoke, que visa otimizar o aproveitamento das aeronaves fazendo convergir vôos de aeroportos menores para um mesmo centro, e a partir daí redistribuindo os passageiros para os demais aeroportos. Assim, ao invés de contar com vôos entre cidades como Rio de Janeiro e Cuiabá, ou Curitiba e Salvador, as empresas fazem com que os passageiros voem destas cidades para São Paulo e a partir daí peguem vôos para os destinos finais. Brasília também se tornou um importante hub para os vôos rumo ao norte-nordeste do país, mas foi o aeroporto de Congonhas - com uma pista bastante restrita e ocupando um área urbana densamente povoada, sem possibilidade de expansão - que acabou se tornando o principal hub do transporte aéreo de passageiros doméstico. 
condutores desta crise seria o movimento dos controladores de vôo, uma vez que a segurança do controle do espaço aéreo seria colocada sob suspeição após o acidente. Os controladores, militares da Aeronáutica, sempre manifestaram sua insatisfação com os baixos salários e as poucas perspectivas dentro da carreira militar, posto que nas funções de controle do espaço aéreo, para as quais se exigia grande especialização, não tinham perspectiva de ascensão. Os protestos assumiram diferentes formatos, tendo começado com uma "operação-padrão" logo após o acidente e culminando com uma greve no dia 30 de março de 2007. A questão dos controladores, que se somaria a situações pontuais enfrentadas pelas empresas aéreas como falhas nos sistemas de check-in ou "manutenções não programadas" dos aviões, além do já citado problema da reforma da pista de Congonhas, levaram os usuários do transporte aéreo a enfrentar longas filas, com horas de esperas nos saguões dos aeroportos que seriam transmitidas ao vivo pelos jornais televisivos.

Este período seria marcado pelo debate entre diferentes instâncias do poder público, empresas e trabalhadores em torno das deficiências do sistema de transporte aéreo brasileiro. Assim, o setor teve a oportunidade de voltar a discutir as suas condições de desenvolvimento em diferentes fóruns, com destaque para as Comissões Parlamentares de Inquéritos criadas na Câmara de Deputados e no Senado para tratar da crise aérea. A análise das posições destes atores sobre diferentes elementos que compuseram o quadro geral do "apagão" permite dimensionar as deficiências, do ponto de vista da qualidade da ação estatal, que conduziram à crise.

Uma das principais dificuldades colocadas em evidência pelo "apagão" disse respeito à falta de investimentos em infra-estrutura de apoio ao vôo, tanto no controle do espaço aéreo quanto nos aeroportos. Como visto anteriormente, a necessidade de aumentar os investimentos nestes dois itens era uma das prioridades apontadas desde as resoluções do CONAC de 2003. Com efeito, os representantes das empresas se colocariam de forma crítica em relação ao que lhes pareceu ter sido uma falta de contrapartida por parte do poder público para os investimentos feitos por elas em modernização da gestão, renovação e otimização das frotas e barateamento das passagens, levando ao aumento no número 
de passageiros transportados. Exemplos desta posição estão nos trechos do depoimento do presidente do Sindicato Nacional das Empresas Aeroviárias, José Márcio Mollo, como segue:

Embora a situação das empresas aéreas brasileiras, hoje, possa ser considerada muito boa, fruto da crença no País, do pesado investimento realizado e a realizar, do forte crescimento da demanda, do expressivo aumento da oferta, da redução acentuada dos preços das passagens, dos ganhos de eficiência da parte dessas empresas, da frota de aviões, que é uma das mais modernas do mundo, existe uma grande preocupação com as condições da infra-estrutura aeronáutica e aeroportuária brasileiras. Essa preocupação encontra sua justificativa na falta de investimento ou no investimento equivocado, por parte do setor público, naquelas infra-estruturas que criaram e criarão enormes gargalos no setor, com sérios prejuízos para as empresas aéreas e também para os passageiros. Esses gargalos, que são a causa principal dos atuais problemas, limitarão o crescimento do setor, com sérias consequiências para o crescimento econômico do País." (MOLLO, 2007, p. 94)

Com efeito, os debates travados deram ênfase ao fato de que os investimentos no controle do espaço aéreo e na infra-estrutura aeroportuária estiveram sujeitos às políticas de contingenciamento de recursos adotadas pelo governo federal ao longo da década, com vistas à manutenção do superávit primário, dentro dos marcos da política de estabilização vigente desde o governo Fernando Henrique. Segundo seus dirigentes, tal contingenciamento atrasou ou não permitiu a realização, por exemplo, de programas de modernização planejados pelo Departamento de Controle do Espaço Aéreo (DECEA), do Ministério da Aeronáutica. A despeito do planejamento de longo prazo feito pelos militares, o depoimento do o diretor do órgão, Brigadeiro Ramon Borges Cardoso, revela que em pelo menos dois anos, o contingenciamento comprometeu os investimentos previstos. ${ }^{17}$ Além dos problemas orçamentários,

17 O Tribunal de Contas da União teria interpretação semelhante, atribuindo aos ministérios responsáveis pela execução orçamentária (Casa Civil e Planejamento) as dificuldades enfrentadas pelo DECEA. A respeito, ver o seguinte artigo publicado no informativo do TCU: "Ministro manifesta preocupação com setor aéreo do país”, TCU União, n. 143, 14/8/2008, p. 5. 
o brigadeiro mencionou também restrições quanto aos recursos humanos disponíveis, como segue:

Na questão de números de suboficiais e sargentos, que são as pessoas responsáveis pela parte técnica, nós hoje estamos restritos a 26.200. E especificamente no caso de controladores, os senhores podem ver que nós não tivemos praticamente crescimento do número de controladores dos anos de 1996 até 2006; foi muito pequeno o crescimento. Em relação às necessidades, foi insuficiente. Tanto que nós não tínhamos controladores em quantidade suficiente para poder suprir todas as posições operacionais de todos os órgãos que hoje estão em funcionamento. E continuamos não tendo. (CARDOSO, 2007, p. 13)

Se no controle do espaço aéreo a questão dos investimentos esteve mais diretamente relacionada às restrições orçamentárias, no caso da infra-estrutura aeroportuária, sob responsabilidade da Infraero, um número maior de variáveis políticas e institucionais entrou em jogo. Não só o contingenciamento de verbas, mas também as prioridades nos investimentos feitos, a possível privatização da empresa em fins dos anos 1990 e desentendimentos com órgãos fiscalizadores (especialmente o TCU) estiveram entre os fatores que contribuíram para as deficiências apontadas pelas empresas. Da mesma forma que no caso do controle do espaço aéreo, os depoimentos dos ex-presidentes da empresa revelaram a existência de um planejamento de longo prazo, legado pelos militares da Aeronáutica. As dificuldades na implementação das ações aparecem nos trechos a seguir, em que Eduardo Pettengil e José Carlos Pereira, respectivamente ex-presidente e presidente da empresa durante o período do "apagão", se referem a diferentes pontos relacionados aos problemas citados anteriormente:

Nós tínhamos um plano de investimento e que estava sendo seguido rigorosamente. Em 1997 entrei e já peguei o plano andado, e dei continuidade. Em 2000, ele estava prosseguindo. (...) E aí eu tenho uma certa preocupação, porque, quando no final já da minha administração, o Governo começou a contingenciar verba da INFRAERO, recurso próprio, não de orçamento, recurso da INFRAERO, para fazer superávit. (PETTENGILL, 2007, p. 89)

Dizem os nossos engenheiros, os nossos especialistas, que um ae- 
roporto não é uma casa popular, que os preços não podem ser os de uma casa popular, que uma pista de pouso não é uma rodovia. $\mathrm{E}$ realmente não é uma rodovia. O Tribunal de Contas trabalha contra isso, e o impasse está criado. Neste momento, nós estamos com 3 ou 4 licitações grandes para serem... editais para serem lançados, como, por exemplo, o novo aeroporto de Florianópolis, que é uma necessidade premente. Santa Catarina está profundamente prejudicada. Brasília. Precisamos urgentemente fazer o segundo satélite de Brasília. Guarulhos. E não lançamos esses editais, porque se nós lançarmos no dia seguinte eles serão impugnados, porque os preços já, o Tribunal de Contas já deixou claro: 'Este preço eu não aceito'. Mas esse é o preço para fazer um aeroporto. Bom, qual é a solução para isso? Não pode continuar a vida toda assim. (PEREIRA, 2007, p. 25)

Tão importante quanto a falta de investimentos, no entanto, foi a falta de uma ação coordenada dentro do governo na gestão do transporte aéreo. Em diferentes oportunidades, os depoentes na comissão da Câmara mencionaram a desarticulação do modelo existente até a virada do século, no qual o controle do espaço aéreo, a infra-estrutura aeroportuária e a regulação das empresas estavam sob a responsabilidade da Aeronáutica. O desmonte deste arranjo teria deixado um vácuo quanto ao planejamento do conjunto do sistema de transporte aéreo. Os trechos a seguir, parte dos depoimentos do ex-presidente da Infraero, Fernando Perrone, e do já citado diretor-geral do DECEA, fazem referência a este aspecto:

Quando houve aquele descompasso com a criação da ANAC, tenho a impressão de que se perdeu um pouco o foco. Quer dizer, foi uma coisa que começou e não concluiu. $\mathrm{E}$, a meu ver, começar e não concluir deixou hoje o setor meio acéfalo, comparado com o que era na época militar. Na época militar, como eu disse, havia um tripé: você tinha um comandante da Aeronáutica e você tinha DEPV, INFRAERO e DAC, muito timidamente coordenados e trabalhando juntos. (...) Quer dizer, a sensação que tenho é de que aquela unidade, aquela gestão que havia antigamente, hoje aparentemente não há. E se não há gestão, enfrentar as questões fica muito mais complicado." (PERRONE, 2007, p. 70)

"Houve um problema de falta de coordenação. Cada órgão fazia seu planejamento de maneira isolada e não tinha ninguém para coordenar. A falta de coordenação fez com que fossem aprovados determinados vôos que o DECEA, na parte de controle de tráfego 
aéreo, e a Infraero, na de infra-estrutura aeroportuária, não tinham capacidade de suportar" (CARDOSO, 2008, p. 37)

A percepção da falta de coordenação entre os órgãos do próprio governo ficaria evidente até mesmo nas iniciativas tomadas pelo núcleo do Poder Executivo para superar a crise do "apagão". O Grupo de Trabalho Interministerial ${ }^{18}$ criado pelo ministro da Defesa em novembro de 2006 para abordar especificamente a questão do controle do espaço aéreo reforçaria, por um lado, o diagnóstico da necessidade de um acompanhamento mais cuidadoso das necessidades tecnológicas, de pessoal e do próprio desenvolvimento da aviação civil. Por outro lado, enfocaram a necessidade "de um planejamento conjunto entre as áreas afetas ao Sistema de Aviação Civil Brasileiro, evitando que volte a ocorrer o hiato entre a Gestão Pública e a Gestão Privada". ${ }^{19}$ O item mais polêmico do relatório, no entanto, seria aquele de número dois, sugerindo a criação de um “organismo civil, subordinado ao Ministro da Defesa, com gestão própria, o qual será o responsável pela gerência das operações aéreas da Aviação Civil no Espaço Aéreo Brasileiro, e pela interatividade com os demais elos da atividade". 20

As estratégias perseguidas pelas empresas também foram objeto de questionamento durante os trabalhos. Representantes

18 O Grupo de Trabalho contou com a participação de representantes de órgãos do governo (Ministérios da Fazenda e do Planejamento, Advocacia Geral da União, Comando da Aeronáutica, ANAC e Infraero), das empresas e dos trabalhadores (controladores e aeronautas).

19 Ver "SNA participa da solução para a crise do controle do espaço aéreo", disponível via http://www.aeronautas.org.br/express/06_12_22_snasolucrise.html, acessado em 23/12/2006.

20 Idem. A despeito do consenso em relação ao diagnóstico e boa parte das ações, o documento foi divulgado com ressalvas apresentadas por diferentes instâncias governamentais. Dentre as principais, estão as ressalvas do Ministério da Fazenda sobre a necessidade de uma avaliação dos custos envolvidos com a criação de um novo órgão e com as medidas de reestruturação das carreiras dos controladores, enquanto o Comando da Aeronáutica se manifestaria de forma contrária à criação de um órgão civil para o controle do espaço aéreo, "porque não é solução para o problema e implica em maiores custos e no prejuízo à eficiência do sistema integrado". A desmilitarização do controle do espaço aéreo de uso civil faria parte do debate sobre o "apagão" durante algum tempo, mas seria eventualmente abandonada. 
governamentais, congressistas e parte da opinião pública acusaramnas de ter sido gananciosas ao adotar modelos baseados na "superutilização" (ou "otimização," do ponto de vista das empresas) do uso dos aviões, na concentração dos vôos em Congonhas, diminuição do espaço entre as poltronas, entre outros aspectos. As empresas, por sua vez, alegariam que ao adotar tais estratégias, haviam sido capazes de oferecer tarifas menores, aumentando a oferta de transporte aéreo no país. Enquanto as autoridades ensaiaram a adoção de medidas mais rígidas de controle sobre as empresas, criando multas por atrasos, restringindo as operações em Congonhas e criando juizados especiais para resolver conflitos nos aeroportos, estas interpelariam o poder público judicialmente, cobrando os prejuízos causados com esperas, vôos cancelados e despesas extraordinárias com alimentação e hospedagem de passageiros e tripulantes durante o "apagão".

Os itens levados às autoridades governamentais desde 2003 a respeito das deficiências na infra-estrutura de apoio ao vôo e demais dificuldades enfrentadas pelas empresas foram, de certa forma, obscurecidas pela expressiva melhora no desempenho do setor a partir de 2004. A falta de atenção à capacidade estatal para lidar com o novo dinamismo assumido pelo setor, no entanto, cobrou seu preço com uma crise sem precedentes no transporte aéreo brasileiro. O refluxo do movimento de protesto dos controladores, a redistribuição das rotas domésticas, reduzindo parcialmente a pressão sobre o aeroporto de Congonhas, ao lado da redução no ritmo de crescimento após o apagão, que a recente crise econômica veio reforçar, permitiram uma acomodação do setor nos dois últimos anos. Uma nova rodada de investigação deve procurar identificar os investimentos feitos na atualização do aparato estatal responsável pelo setor, de forma a avaliar a medida em que as lições aprendidas com o "apagão" contribuíram para a adaptação do transporte aéreo brasileiro aos desafios do capitalismo do século XXI.

\section{Conclusão}

Analisando o desempenho do mercado ao longo dos últimos anos, deve-se destacar que as medidas de caráter mais intervencionis- 
ta tomadas entre 2003 e 2004 não impediram o mercado de crescer e tampouco impediu que novas empresas surgissem, pois foi justamente entre 2004 e 2005 que a BRA, Oceanair e Webjet passaram a disputar o mercado doméstico. Certamente, impacto mais expressivo do ponto de vista do funcionamento do mercado teve o conjunto de deficiências que levaram ao "apagão", gerando perdas para as empresas, eventualmente levando um setor em expansão, que reduziu os preços das passagens e manteve a lucratividade, a sofrer uma nova onda de perdas e redução nas taxas de crescimento. Neste sentido, a trajetória do setor de aviação comercial foi um laboratório que permitiu perceber os limites de uma abordagem focada exclusivamente na lógica do mercado e a necessidade de uma abordagem que pense a interação dos agentes econômicos a partir de uma estrutura social mais ampla, na qual o Estado ocupa um lugar de destaque.

A literatura existente sobre transporte aéreo no Brasil, que cresceu em quantidade e qualidade nos últimos anos, tem se pautado por uma perspectiva ainda muito comprometida com a abordagem dicotômica sobre a relação entre Estado e mercado que marcou o auge das reformas. Por um lado, condenou as medidas de perfil mais intervencionistas tomadas no início do governo Lula, sob o argumento de que representaram indícios de "instabilidade regulatória", entendida como um desincentivo ao investimento privado. Por outro lado, preconizou o incremento no processo de liberalização e flexibilização das regras do setor, como melhor alternativa para fazer frente aos desafios que o "apagão" veio revelar (Cf. Salgado e Guimarães, 2003; Oliveira, 2005, 2006).

Sem negar que a estabilidade regulatória seja um dos fatores que podem contribuir para o bom funcionamento do mercado e que a possibilidade de que novas rodadas de liberalização e flexibilização nas regras do setor, inclusive estendendo-as para as áreas de infraestrutura (com a privatização ou, pelo menos, a descentralização da gestão dos aeroportos), possam trazer ganhos para o conjunto da sociedade brasileira, este trabalho procurou chamar atenção para uma dimensão alternativa: independente da estabilidade das regras e de quão liberalizado/flexibilizado seja o mercado de transporte aéreo no Brasil, ele não poderá prescindir de um aparato estatal robusto que seja capaz de acompanhar o seu dinamismo. Por outro 
lado, se tal robustez envolve necessariamente capacidade técnica, ela também passará por capacidade de lidar politicamente com a complexidade dos interesses em jogo.

\section{Referências}

ANDRADE, T. A crise da Varig/Tam e o uso do code share. In: Salgado, Lucia e Motta, Ronaldo (orgs.). Regulação e concorrência no Brasil: governança, incentivos e eficiência. Rio de Janeiro: IPEA, 2007.

ARBIX, G. Da liberalização cega dos anos 90 à construção estratégica do desenvolvimento. Tempo Social, v. 14/n. 1, p. 1-17, 2002.

BACHA, E. Perspectivas econômicas brasileiras em regime de feijão com arroz à la Marcílio. In: Jaguaribe, H. et al.. Economia e política da crise brasileira: o pensamento da equipe Fernando Henrique. Rio de Janeiro: Rio Fundo, 1995.

BERGER, S. \& DORE, R. (Orgs.). National diversity and global capitalism. Ithaca e London: Cornell University Press, 1996.

BLOCK, F. The roles of the State in the economy. In: Smelser, N. \& Swedberg, R. (Orgs.). The handbook of economic sociology. Princeton, NJ: Princeton University Press/New York: Russell Sage Foundation, 1994.

BOURDIEU, P. Le champ économique. Actes de la Recherche en Sciences Sociales, n. 119, 1997.

CHANG, Ha-Joon. Chutando a escada: a estratégia do desenvolvimento em perspectiva histórica. São Paulo: Unesp, 2004.

. Rompendo o modelo. Uma economia política institucionalista alternativa à teoria neoliberal do mercado e do Estado. In: ARBIX, G.; COMIN, A.; ZILBOVICIUS, M. \& ABRAMOVAY, R. (Orgs.). Brasil, México, África do Sul e China: diálogo entre os que vieram depois. São Paulo: Ed. Unesp e Edusp, 2002, p. 99-134.

DINIZ, E. El post-consenso de Washington: globalización, Estado y desarollo reexaminados. Boletín Brasil (Centro de Estudios Brasileños Ortega y Gasset), v. 4/n. 1, 2007. 
. Empresários e Governo Lula: percepções e ação política entre 2002 e 2006. In: Anais do V Workshop Empresa, empresários e sociedade: o mundo empresarial e a questão social. Porto AlegreRS, 2 a 5 de maio, 2006.

. Globalização, reformas econômicas e elites empresariais. Rio de Janeiro: FGV, 2000.

DINIZ E. \& BOSCHI, R. A difícil rota do desenvolvimento: empresários e a agenda pós-neoliberal. Belo Horizonte: UFMG/Rio de Janeiro: IUPERJ, 2007.

DRACHE, D. From Keynes to K-Mart. Competitiveness in a corporate age. In: BOYER, R. \& DRACHE, D. (Orgs.). States against markets. The limits of globalization. London e Nova Iorque: Routledge, 1996.

EVANS, P. Embedded autonomy. States and industrial transformation. Princeton, NJ: Princeton University Press, 1995.

FERER, A. Development and underdevelopment in a globalized world: latin american dilemmas. In: EMMERIJ, L. (Org.): Economic and social development into the XXI Century. Washington: InterAmerican Development Bank, 1997.

FLIGSTEIN, N. The architecture of markets. An economic sociology of twenty-first century capitalist societies. Princeton: Princeton University Press, 2001.

FRANCO, F. et al.. Recent deregulation of the air transportation in Brazil. Brasília: Secretaria de Acompanhamento Econômico/ Ministério da Fazenda (Documento de Trabalho n. 12), 2002.

GUIMARÃES, E. \& SALGADO, L. A regulação do mercado de aviação civil no Brasil. Rio de Janeiro: IPEA (Notas Técnicas, 2), 2003.

HICKS, A. \& KENWORTHY, L. Cooperation and political economic performance in affluent democratic capitalism. American Journal of Sociology, v. 103/n. 6, 1998.

HOLLINGSWORTH, J., ROGERS \& BOYER (Orgs.). Contemporary capitalism: the embeddedness of institutions. Cambridge: Cambridge University Press, 1997.

HOLLINGSWORTH, J.; SCHMITTER, P. \& STREECK, W. (Orgs.). Governing capitalist economies: performance and control of economic sectors. New York e Oxford: Oxford University Press, 1994. 
KIRSCHNER, A.; GOMES, E. \& CAPPELLIN, P. (Orgs.). Empresa, empresários e globalização. Rio de Janeiro: Relume Dumará/FAPERJ, 2002.

LEOPOLDI, M. Democracia e reformas econômicas no Brasil. Desregulando o setor de seguros e previdência privada na Nova República (1985-1999). In: Kirschner, A. M. e Gomes, E. (Orgs.). Empresa, empresários e sociedade. Rio de Janeiro: Sette Letras, 1999.

MAXFIELD, S. \& SCHNEIDER, B. (Orgs.). Business and the State in developing countries. Ithaca, NY: Cornell University Press, 1997.

MONTEIRO, C. Empresários e ação política no contexto das reformas neoliberais: o caso da aviação comercial. Revista de Sociologia e Política, v. 16, supl., 2008, p. 159-180.

. Estratégias sindicais no contexto das reformas para o mercado: o caso dos trabalhadores da aviação comercial. Enfoques Online. v. 4/n. 2, 2006b. Disponível via www.ifcs.ufrj.br/ ppgsa/ Revista_Enfoques, consultado em 08/02/2007.

. A dinâmica política das reformas para o mercado na aviação comercial brasileira. Rio de Janeiro: PPGSA/IFCS/UFRJ, Tese de Doutorado em Sociologia, 2004.

OLIVEIRA, A. Liberalização econômica e universalização do acesso no transporte aéreo: é possível conciliar livre mercado com metas sociais e ainda evitar gargalos de infra-estrutura? São José dos Campos-SP: NECTAR/ITA (Documento de Trabalho n. 014), 2006. Disponível via www.nectar.ita.br, consultado em 10/05/2007.

. Performance dos regulados e eficácia do regulador: uma avaliação das políticas regulatórias do transporte aéreo e dos desafios para o futuro. São José dos Campos, SP: NECTAR/ITA (Documento de Trabalho n. 007), 2005. Disponível via www.nectar. ita.br, consultado em 10/5/2007.

PÊGO FILHO, B. Setor aéreo e as empresas brasileiras: situação atual e perspectivas. Boletim de Conjuntura do IPEA, n. 59, 2002, p. 73-78.

POLANYI, K. The great transformation. The political and economic origins of our time. Boston: Beacon Press, 1944.

PRADO, M. Concessão pública: um empreendimento público comercial. Revista do BNDES, v. 3/n. 5, 1996. 
RIGOLON, F. Regulação da infra-estrutura: a experiência recente no Brasil. Revista do BNDES, n. 4/n. 7, 1997, p. 123-150.

RPK Consultoria. Entraves à competitividade das empresas aéreas brasileiras. Junho de 2008, disponível via http://www.snea.com.br/ estudos/Apresentação\%20para\%20a\%20ANAC.pdf (consultado em $10 / 11 / 2008)$.

SOUZA, R. \& MOREIRA, T. Reflexões sobre a concessão de serviços públicos. Revista do BNDES, v. 2/n. 4, 1995.

STEINER, P. A Sociologia Econômica. São Paulo: Atlas, 2006.

TÁPIA, J. Conselho de Desenvolvimento Econômico e Social: os desafios da construção institucional. In: Diniz, E. (org.). Globalização, Estado e desenvolvimento: dilemas do Brasil no novo milênio. Rio de Janeiro: FGV, 2007.

VELASCO E CRUZ, S. Alguns argumentos sobre reformas para o mercado. Lua Nova, n. 45, 1998, p. 5-27.

WEISS, Linda. The myth of the powerless state. Ithaca, NY: Cornell University Press, 1998.

\section{Outras referências}

CARDOSO, R.B. Depoimento à CPI da Crise do Sistema de Tráfego Aéreo. Brasília: Câmara dos Deputados, 24/5/2007.

. Entrevista. Aeromagazine, n. 165, fevereiro de 2008.

MOLLO, J. Depoimento à CPI da Crise do Sistema de Tráfego Aéreo. Brasília: Câmara dos Deputados, 5/6/2007.

PEREIRA, J.C. Depoimento à CPI da Crise do Sistema de Tráfego Aéreo. Brasília: Câmara dos Deputados, 12/6/2007.

PERRONE, F. Depoimento à CPI da Crise do Sistema de Tráfego Aéreo. Brasília: Câmara dos Deputados, 14/6/2007.

PETTENGILL, E. Depoimento à CPI da Crise do Sistema de Tráfego Aéreo. Brasília: Câmara dos Deputados, 12/6/2007. 


\begin{abstract}

\section{State and market in post-reform Brazilian air transportation}

The changes that have taken place in Brazilian air transportation following the cycle of "market reforms" have turned this sector into an object of growing interest. This interest, in turn, has led to the emergence of a broad literature on the subject, characterized by the emphasis on an agenda of liberalization and the critique of State activism. The goal of the present article is to promote a confrontation between the different interpretations that have been made, incorporating the contributions of approaches inspired in Economic Sociology and in institutionalist analyses in order to draw attention to the importance that political variables, and the State in particular, have for economic performance. The post-reform context is characterized by an initial moment of greater State activism regarding air transportation, through re-initiation of stricter regulatory mechanisms and the re-opening of channels of dialog between state actors and firms. This is followed by a second moment in which state activism is abandoned, at the same time that the sector demonstrates expressive rates of growth, pushing it beyond its existing capacity and flight support infrastructure. This culminated in the episode known as the "apagão aéreo" (aerial black out) Analysis of testimonies of state and private sector actors regarding the "blackout" enables us to identify the flaws in the responsible state apparatus as one of the factors that led to the "blackout". Our conclusions draw attention to the importance of taking political factors into consideration, and particularly the role of the State, in the development of air transportation in Brazil.
\end{abstract}

Keywords: commercial aviation, politics and economics, regulation, Economic Sociology, Historical Institutionalism. 
